\section{DENTAL TECHNICIAN APPOINTED CHAIR OF DCP ADVISORY BOARD}

The Faculty of General Dental Practice (UK) (FGDP(UK)) has welcomed Tony Griffin as the new Chair of its Dental Care Professional (DCP) Advisory Board. A former President of the Dental Technicians Association and founder member of the FGDP(UK) DCP Advisory Board, Tony has been active for over 30 years in supporting training courses for the dental team.

Among his achievements in the FGDP(UK), Tony has played a key role in the development of a route to registration in clinical dental technology and was part of the team that developed the key skills in primary dental care assessment for DCPs. He takes over the post from Janet Goodwin, who stepped down after being appointed to the General Dental Council.

The FGDP(UK) has also appointed John Stanfield to the post of Vice Chair of the DCP Advisory Board. John has represented dental hygienists on the Board since 2006 and is also an assessor for the DCP key skills assessment. Both John and Tony are also members of the editorial board for the FGDP(UK)'s DCP journal, Team in Practice.

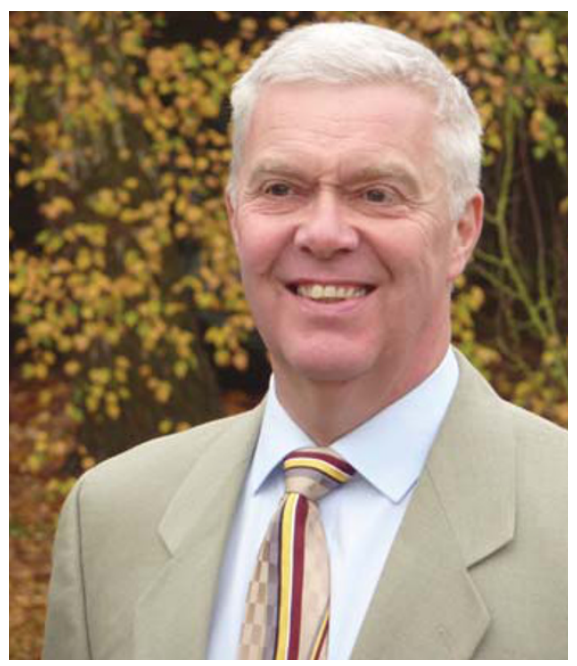

Tony Griffin

\section{BUSINESSMAN OF THE YEAR}

Arshad Ali, clinical director of The Scottish Centre for Excellence in Dentistry in Govan, Glasgow, has been named businessman of the year at the Scottish Asian Business Awards.

The dental surgeon was presented with his award by Jim Shaw, senior partner at Clydesdale Bank at the ceremony at Glasgow's Crowne Plaza hotel. Since qualifying as a dentist in 1978, Arshad Ali has been at the forefront of restorative dentistry, and was one of the first dental surgeons to introduce implantology to patients in the UK. He is also internationally renowned for

the rehabilitation of oral cancer and trauma patients.

In April 2009, Mr Ali opened the £3 million Scottish Centre for Excellence in Dentistry (SCED), a private dental clinic specialising in dentistry, implantology, facial rejuvenation, plastic surgery and hypnotherapy.

He said, 'It is an absolute honour to be awarded the top businessman award. Opening SCED earlier this year was a major milestone in my career and to be recognised with this prestigious award makes all the hard work worthwhile.'

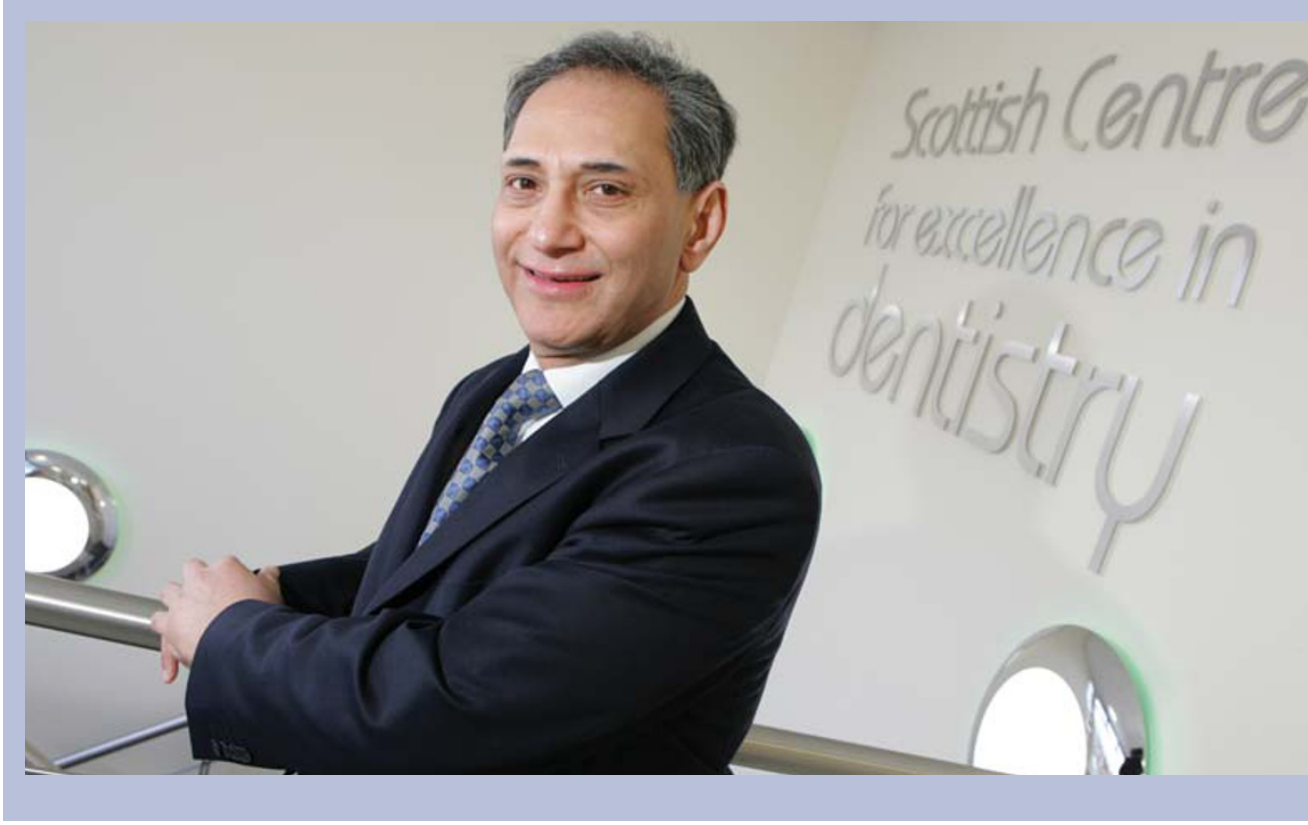

\title{
BDA CALLS FOR EVIDENCE BASE REVIEW
}

The British Dental Association (BDA) has called for a full review of the evidence base for the HTM 01-05 guidance document on decontamination in dental surgeries.

The BDA has written to the Department of Health (DH) renewing its 2007 call for a National Institute for Health and Clinical Excellence (NICE) review of the evidence, after it emerged that three areas of the guidance have already been amended before the document is even printed.
The three changes to the guidance that have already been made are that the use of potable water for the rinse stage of decontamination is now permitted, the period for which instruments can be stored after they have been processed in a validated vacuum sterilizer has been increased from 30 days to 60 days and the requirement for two sinks for decontamination has been revised, to allow the option of two bowls incorporated into a single unit instead. 